\title{
ANTÔNIO DE ALCANTARA MACHADO E AS MODINHAS PAULISTANAS: SOBRE AS RAÍZES DA NARRATIVA POPULAR NA CIDADE DE SÃO PAULO
}

\section{Gabriel Caio Correa Borges \\ Doutorando em Ciências da Literatura pela Universidade Federal do Rio de Janeiro}

(UFRJ)

gabrielcaioborges@gmail.com

\section{RESUMO}

Com base em uma publicação rara de Antônio de Alcantara Machado, pretendemos localizar a origem de certa narrativa que seria associada aos fazeres ordinários da cidade de São Paulo nas chamadas modinhas paulistanas. Expressividades que surgem do encaixe feito por pessoas comuns, que agregavam a canções famosas líricas inspiradas no noticiário, inspiraram posteriormente variadas formas de narratividade urbana sobre a cotidianidade paulistana. Em vista desse encadeamento, tomamos como exemplar o próprio Antônio Alcantara Machado, que assume a influência das modinhas paulistanas, cuja investigação será realizada neste artigo.

Palavras-chave: narrativa, modinhas paulistanas, Antônio de Alcantara Machado, São Paulo.

\section{ABSTRACT}

With basis on a rare publication of Antônio de Alcantara Machado, we intent to search the origin from a certain narrative associated with the ordinary productions from the city of São Paulo, called "modinhas paulistanas". Expressivities who appears from the joint made by common people, wich incorporate into famous songs lyrics inspired from the news, that would inspire in the future various forms of urban narrativity about the São Paulo's everyday. Consider this successiveness, we will use Antônio de Alcantara Machado as an example of someone who takes the influence from the so called "modinhas paulistanas", wich the investigation will be realized in this article.

Keywords: narrative, modinhas paulistanas; Antônio de Alcantara Machado; São Paulo. 


\section{Introdução}

Em um documento raro, cuja publicação pode ser encontrada somente em uma antiga edição da Revista do Arquivo Municipal de São Paulo do ano de 1935, Antônio de Alcantara Machado se propõe ao registro do que ele denomina as "modinhas paulistanas", apresentando um panorama geral de suas características e um apanhado de algumas de suas líricas. Publicado postumamente, sua presença em uma publicação oficial do Departamento de Cultura da cidade é indicativo do que era valorizado pela instituição a partir da liderança de Mário de Andrade, que veio a assumir a diretoria do departamento naquele mesmo ano. É provável que o encaminhamento proposto por Mario de Andrade, ao conduzir pesquisas com base na etnologia e no folclorismo, teria influenciado para que o texto de Alcantara Machado tivesse saído na décima sétima edição da Revista do Arquivo Municipal. Pois é precisamente o enfoque etnológico que é utilizado pelo autor para evidenciar o fenômeno cultural de que trata.

Porém, da importância dessa coleta para o autor de "Brás, Bexiga e Barra Funda", cabe algo que vai além de sua intenção de estudo. Ao iniciar o texto, Alcantara Machado diz que o que o motivou a pesquisar as referidas modinhas paulistanas é a ligação afetiva e artística que teria com elas e que viriam a influenciar a sua própria identidade como artista.

Incapaz, mas incapaz, de recitar o verso mais famoso sem quebrar em pedaços, não entendendo absolutamente nada de arte poética, senhor ou vitima de desarocoçoadora falta de vocação para bardo, o autor nas noites mais expiatórias de insônia estética não é atormentado por uma única escorregadela dessas desculpas de olhos no chão como pecadilhos da mocidade: espinhas, gabolice e sonetos. Não resta 
dúvida que aos dezesseis anos compoz um hino de futebol para ser cantado com a música "Rolinha do Sertão". Pois é. Mas isso entrava nas suas funções de primeiro secretário do clube. Nem o poeta por imposição do cargo se lembraria mais do caso se muito tempo depois não viesse a conhecer os rapsodos do Tiete paulistano. Então o hino do A. A. América flutuou nas lembranças dele. E ele viu ali várias coincidências: versos encomendados, assunto contingente, adaptação à música de uma canção em voga, nenhuma intenção artística ainda remota (porque não pode ser confundida com ela o empenho natural do trabalhador em executar bem o seu trabalho). E sentiu, então, sim, sua vocação para poeta do Brás, Moóca e Belenzinho. Como quem descobre em si mesmo mais uma prova de sua cidadania (MACHADO, 1935, p. 190).

Sentimento afetivo que se mescla com o intelectual, a imersão no imaginário popular urbano das modinhas paulistanas pode oferecer pistas para a compreensão da própria obra de Alcantara Machado no que diz respeito ao seu papel como pioneiro da crônica na cidade. Afinal, a leitura de sua prosa mostra a afinidade com a vivência a rés do chão em uma São Paulo que iniciava sua modernização. Quando é realizada a comparação entre as características gerais das modinhas paulistanas elencadas por Alcantara Machado e a própria obra deste, percebe-se não apenas um olhar semelhante sobre a cidade, mas também a confluência dos elementos e temas norteadores na composição textual.

A simbiose de Alcantara Machado com as modinhas paulistanas também seria reveladora para a compreensão do imaginário retratado na canção e na literatura popular da cidade. O que fora introduzido nessas primeiras formações seria desenvolvido na sátira lírica de Juó Barnabaré e no cancioneiro de Adoniran Barbosa. Tais autores, que iriam explorar principalmente o uso da palavra oral, tiveram o caminho aberto pelas modinhas paulistanas, que já procediam numa primeira tentativa de representar o 
sotaque imigrante na poética popular. Partindo desse panorama, intentamos com este artigo compreender como a relação de Antônio de Alcantara Machado com as modinhas paulistanas foi exemplar não apenas de um episódio de troca de influências entre música e literatura, mas também de como tal intercâmbio seria uma constante na São Paulo da primeira metade do século XX.

\section{Aspectos teóricos sobre as modinhas paulistanas}

Acerca da arte popular no entremeio da relação entre música e literatura, Antônio de Alcantara Machado comenta o fenômeno das modinhas paulistanas como algo que reverte o encaminhar comum da criação artística, ou "contrário do que se dá nas esferas superiores: o compositor vem antes do poeta" (MACHADO, 1935, p. 191). Este axioma introduz os mecanismos da modinha paulistana que operavam com os fragmentos de uma cultura urbana e moderna nascente. Afinal, a matéria prima dessas modinhas são precisamente a canção de massas e a notícia jornalística; dois elementos onipresentes na sociedade moderna, cuja ascensão é sempre acompanhada pela demanda de mediatização. Trabalhando nesses documentos como já acabados, essas modinhas realizavam uma síntese em que o cancioneiro popular servia de significante e a notícia de significado. Ou seja, os compositores utilizavam as melodias de canções já consagradas e ajustavam uma nova lírica baseada nos casos relatados na imprensa marrom da época nelas; no caso, relatos exagerados de violência urbana.

Mera redução de um fato em autentico, desconhece a ficção. A miséria (em regra a miséria) diária da cidade oferecida, condensada em quadras fáceis de guardar. (...) A 
fonte é o jornal, notadamente a crônica de polícia. O trovador faz o papel de repórter. E como esse repórter é povo e se dirige unicamente ao povo escolhe naturalmente a modinha. Toda gente sabe: verso e música são expressões de arte mais próximas do analfabeto. Conjugados assumem um poder de comunicação que fura a sensibilidade mais dura. (MACHADO, 1935, p. 191).

Já sobre a recriação de canções já acabadas como "molde":

O trovador paulistano é exclusivamente versificador. Isso sem exceção nenhuma. A música não é a que compõe, não é comentário ou acompanhamento, em geral nada tem a ver com as palavras. Utiliza-se de tangos, maxixes e canções de sucesso no momento que ficaram na memória popular. De maneira que já tem o molde pronto. Verseja de ouvido trauteando a música escolhida ou então guiando-se servilmente pela letra desta no que convém. Seguindo rigorosamente a disposição dos versos e quando fácil a das consoantes da letra original das canções a cuja música adapta a modinha (MACHADO, 1935, p. 191).

Operações ordinárias de uma urbanidade nascente, o surgimento das modinhas paulistanas diz respeito a um período onde as normas da modernidade se avizinhavam, porém, não estavam plenamente estabelecidas e confusas para uma população que ainda as estranhava. Em certo sentido, não difere muito do que aconteceu no samba urbano carioca após "Pelo Telefone", em que a incompreensão sobre o que vem a ser direitos autorais levou a episódios como as apropriações de sambas tradicionais por compositores como Sinhô e a compra de autorias. Contudo, diferentemente do que ocorria no Rio de Janeiro, esses movimentos de apropriação se constituem como o próprio fundamento do fazer.

Essa é uma consequência deveras normal de um cenário cuja nascente e formidável modernidade dificulta a continuidade de qualquer fazer que seja amparado em alguma 
tradição. Uma nova situação que ainda está consolidando suas regras e se apresenta confusa para a crescente população urbana é o que caracteriza os primeiros momentos de transformação de São Paulo em uma metrópole. Logo, o encaixe amadorístico e improvisado de diversos signos que a modernidade apresentava surge como possibilidade de ação tática para a formação de uma cultura ordinária em um cenário imposto. Tal fenômeno se alinha naquilo que Levi-Strauss denominou como a atividade do bricoleur que trata exatamente de se organizar, agir e modificar conforme os limites de uma ordem exterior dada.

Aliás, subsiste entre nós uma forma de atividade que, no plano técnico, permite conceber perfeitamente aquilo que, no plano da especulação, pôde ser uma ciência que preferimos antes chamar de "primeira" que de primitiva: é aquela comumente designada pelo termo bricolage. Em sua acepção antiga, o verbo bricoler aplica-se ao jogo de pela e de bilhar, à caça e à equitação, mas sempre para evocar um movimento incidental; o da pela que salta muitas vezes, do cão que corre ao acaso, do cavalo que se desvia da linha reta para evitar um obstáculo. E, em nossos dias, o bricoleur é aquele que trabalha com suas mãos, utilizando meios indiretos se comparados com os do artista (2012, p. 33).

A evocação que o antropólogo faz do bricoleur é comparativa. Ele entende essa atividade como o que existe de mais próximo hoje das faculdades do pensamento dito místico cultivado por povos autóctones. O bricoleur surge como um denominador comum entre o fazer científico e as atividades ordinárias que aparecem na tentativa de contato e compreensão dos seres humanos com o meio. Essa atribuição dada pelo autor permite à arte reencontrar sua condição como fazer, operando dialeticamente em instâncias como o mítico e o científico, o erudito e o vulgar, e, mais importante para nosso ponto, a tradição e a ruptura. Ao martelar o discurso informativo nas melodias das canções de 
massas, as modinhas paulistanas se propunham exatamente a possibilitar o surgimento de uma tradição que se volta por e para o novo espaço moderno, por mais paradoxal que isso possa parecer.

A força desse legado pode ser compreendida na forma de representação da cidade. Embora o sensacionalismo lírico das modinhas paulistanas ainda pudesse ser caracterizado como uma expressão rudimentar, essas representações da violência urbana - quase sempre de crimes passionais - são uma tentativa inicial de conciliar informação com experiência. Afinal, no lugar de oferecer as vítimas dos crimes relatados o esquecimento das páginas dos jornais, as modinhas narram seu infortúnio, transformando-os em causos referentes à cotidianidade urbana e considerando vítimas e algozes como personagens cujo nome carrega uma história que merece ser contada. São características que se mostram presentes em diversas das modinhas registradas por Alcantara Machado. Caso dessa que foi registrada em cima do tango "Milonguita", que substitui a letra em espanhol do uruguaio Samuel Linning por uma peça em português dividida em quadras e de forte teor narrativo.

Na capela da Quinta Parada

Numa tarde do mês de dezembro

Se casaram dois jovens amantes

Cujo filho nascera em novembro

Conheceram-se no carnaval

Mas estando então desempregados

O moço só reparou o mal

Depois que se viu bem colocado

Estribilho

Deste mundo

O perigo é a mulher 
Abusando de sua força

Nada dá mas tudo quer

Sua beleza

vive só de fazer mal

Mortes suicídios desgraças

Como um báratro fatal

Brasileira filha de espanhóis

Com cabelos cor de carvão

E dois olhos que nem dois faróis

Leonor despertava paixão

No princípio o casal foi feliz

A mulher sempre em casa na lida

E o correto José Passarella

Só pensando em ganhar sua vida (...)

A ventura porém não durou

Leonor conspurcando deu lar

De repente virou janeleira

Como moça que quer se casar

A vizinhança vendo seu jogo

Quis até avisar Passarella

Pois quem é boa mãe de família

Nunca pensa em viver na janela (...)

Uma tarde depois do serviço

Passarella cansado chegou

Em sua casa que ao sol resplendia

E uma carta cruel encontrou

Nessa carta Leonor Ihe dizia

Com palavras de frio desdém

Que deixava o marido e seu filho

Pois aos dois não queria mais bem (...)

Passarella na noite seguinte

Desvairado com justa razão

Encontrou Leonor que saia

De uma mais que suspeita pensão (...)

Com dois tiros matou a perjura 
Depois vendo o seu sonho desfeito

Liquidando com tanta amargura

Uma bala meteu no seu peito (MACHADO, 1935, 212-214).

Do caso retratado pelo autor anônimo, é evidente a influência do discurso noticioso sobre a forma da representação urbana. Não só a canção se preocupa em responder o questionário base de qualquer informação jornalística - quem, quando, onde, porque e como -, como também se baseia no sensacionalismo que extraia sua matéria prima dos casos de violência cotidiana. Contudo, o imediatismo não é priorizado, pois a informação central do caso, o crime passional seguido de suicídio, é apresentada somente na última quadra da canção. Esse detalhe leva a um cuidado diferenciado ao tratar da informação. A lógica do lead noticioso, ao dar as informações básicas já no primeiro parágrafo, obriga a um trato frívolo e fugaz da informação. Submeter esta ao final do texto permite esmiuçar as nuances do acontecimento permeado pela experiência humana geralmente ignorada ou desprezada pelo texto informativo. Pois o indicativo dos nomes do casal, Leonor e José Passarella, não são apenas detalhes da informação, mas elementos básicos para recontar a história da vida desses dois personagens e como ela culminou na tragédia mencionada. Cabe menção também ao moralismo do autor que leva o teor da lírica a ter certa simpatia com o assassino e a reprovar o comportamento da mulher adúltera.

Essa devolução da experiência ao relato é algo mais importante do que pode parecer. Pois no que diz respeito à natureza da informação como ação da modernidade sobre o saber, ela surge para substituir a tradição narrativa que não encontra mais lugar em um paradigma marcado pela atomização social e pela densidade e velocidade dos acontecimentos. Ao preencher a demanda por saber em um mundo caracterizado de tal forma, a informação lima a experiência, seja pela ética jornalística que coloca a 
objetividade como um ideal a ser alcançado, seja porque o fluxo da cotidianidade moderna é caracterizado pela aniquilação das formas de experiência.

O saber que vinha de longe - seja espacialmente, das terras estranhas, ou temporariamente, da tradição - dispunha de uma autoridade que lhe conferia validade, mesmo que não fosse subsumível ao controle. A informação, porém, aspira a uma verificabilidade imediata. Para tal, ela precisa ser, antes de mais nada, "compreensível de si para si". Muitas vezes não é mais exata que os relatos antigos. Mas enquanto esses relatos recorriam frequentemente ao miraculoso, é indispensável que a informação soe plausível. Nisso ela se revela incompatível com o espírito da narrativa Se a arte da narrativa é hoje rara, a difusão da informação tem uma participação decisiva nesse declínio (BENJAMIN, 2012, p. 219).

Conforme a definição de experiência proposta por Walter Benjamin, assim como de suas considerações sobre a narrativa e a informação, ao relacionarmos as modinhas paulistanas como uma formação narrativa, esta diz respeito a uma forma diferenciada de experiência quando comparada aquela vinculada à tradição. Afinal, a tese benjaminiana sobre a narrativa dizia respeito sobre certa experiência coletiva paradigmática dos tempos pré-modernos e sobre o pertencimento coletivo como vetor da significação humana no tempo e espaço. No que toca a modernidade, o que passa a se compreender como experiência é o choque do indivíduo que vai em contraponto às massas alienadas da rotina urbana, ator que traça sua própria história e legado se destacando da multidão (BENJAMIN, 1994).

Nessa tentativa de reconciliar a experiência às novidades das informações, as modinhas paulistanas são talvez a encarnação mais ordinária de um fenômeno representativo da produção textual urbana do começo do século XX. Da indefinição do espaço moderno, surgiu nesse período uma produção literária diversificada cuja 
preocupação era sintetizar no valor informativo a vivência propiciada pela cotidianidade urbana. É tal movimento que leva ao jornalismo literário no começo do século XX, com nomes como João do Rio, no Rio de Janeiro, e Sylvio Floreal, em São Paulo, encarnando flaneurs que se aventuram nos lugares ocultos de suas cidades. Mas foi nas crônicas impressas que essa síntese obteve o seu produto mais bem acabado. Conforme o termo crônica foi significado no Brasil, ele pode ser entendido como um gênero "ao mesmo tempo jornalístico e literário. Uma forma híbrida, portanto, vivendo em condição ambivalente" (BULHÕES, 2007, p. 47). Por se integrar ao corpo do jornal impresso, ocupando um pequeno, mas essencial, espaço, a crônica também comungaria com as lógicas de consumo e de descarte sintomáticas desse meio. Porém a característica da crônica de representar as minúcias da cotidianidade urbana, aproximando o jornalismo da fala, dos sentimentos e percalços do cidadão comum, acaba por fazê-la superar alguns dos limites estruturais do jornal; principalmente por ter na redescoberta da experiência seu principal fator de significação. Ao comentar sobre a obra do cronista Rubem Braga, David Arrigucci Jr. é categórico ao afirmar a presença de tal característica na crônica.

É que esse mundo da experiência pessoal, rica e complexa, tal como se revela no símbolo que o olhar melancólico do cronista colhe da fugacidade, aparece no jornal ou na revista, isto é, num veiculo que não se presta a exprimir experiência, mas, sim, liquidá-las, substituindo-as pela pura informação. Paradoxalmente, Braga é um cronista que discrepa no espaço dos periódicos. De certo modo, é arcaico ali, onde exatamente surgiu para não mais sair. Grande parte do encanto do das coisas que escreveu se deve ao fato assinalado do que ele narra histórias do que já não tem história, do que se perde irremediavelmente. Mas grande parte desse encanto deriva também do fato de o próprio cronista ser alguém que se desfaz em meio às tropelias brutalmente informativas do jornal (ARRIGUCCI JR., 1979, p. 164). 
As modinhas paulistanas partilham muitas características comuns com a crônica. Ambas se apegam a mecanismos midiáticos - formalmente na crônica, informalmente nas modinhas - para conciliarem a fugacidade urbana à representação da experiência. Contudo, no que opera no interior desse aspecto, certamente chama atenção à minúcia com que esses dois gêneros tratam das nuances da palavra oral. São manifestações que procuram registrar a dinâmica da palavra oral no que condiz a relação da experiência com a linguagem; compreendendo as mutações, variações e mesclas que permeiam a fala nos choques provenientes da multiplicidade urbana. No que toca a relação com esse aspecto, o crítico Massaud Moises denomina na crônica esse movimento de monodiálogo, que define o cronista como alguém que "esta em diálogo virtual com um interlocutor mudo, mas sem o qual a sua (ex)incursão se torna impossível" (1982, p. 257). Já sobre as modinhas paulistanas, Alcantara Machado identifica seu uso da linguagem como algo ao mesmo tempo "vulgar e preciosa" (1935, p. 192), no que percebe que o trabalho de encaixe lírico do compositor deve corresponder à própria formação linguística do autor.

\section{Repercussões da arte ordinária na literatura urbana}

Como parte das primeiras formações de atividade ordinária com fins de expressividade, as modinhas paulistanas enunciariam alguns dos alicerces pelos quais a arte popular paulistana seria conhecida. De fato, ao comentar sobre o estudo de Alcantara Machado, José Vinci de Moraes compreende que o legado das modinhas paulistanas em suas características fundamentais pode ser rastreado na canção popular feita na cidade. 
Aparentemente, essas temáticas tão urbanas, tecendo relações entre elementos universais e particulares e contadas por meio de forte discurso narrativo e personalizado, não ficaram restritos ao âmbito das modinhas paulistanas. Todos esses elementos parecem ter se consolidado definitivamente em parte da cultura popular paulistana, marcando sua cultura musical. De certa forma, consagram-se de modo individual ou coletivo, sobretudo na obra de dois autores de perfil fortemente vinculado ao cotidiano da cidade: Adoniran Barbosa e Paulo Vanzolini (MORAES, 2000, p. 190).

Sem dúvidas, esse rastro mostra-se bem visível na canção da cidade. Presente na persona ítalo-caipira de Adoniran Barbosa cujo "falar errado" virou representativo de um sotaque múltiplo do paulistano. Também, como já mencionado por Moraes, na valorização da experiência urbana como principal motivo lírico. Mas, no que é evidente sua influência sobre a canção, menos óbvia seria sua influência sobre outras formações artísticas, mais especificamente sobre a literatura.

Essa influência pode ser compreendida no próprio Antônio de Alcantara Machado como pioneiro da crônica urbana para São Paulo. Embora sua produção literária se aproxime mais da forma do conto do que da crônica impressa, ela já reunia algumas das características que viriam a definir a crônica como representação da urbanidade moderna e ordinária. Mais especificamente, o registro do fluxo e variações linguísticas do falar urbano, a valorização narrativa da cotidianidade e a proximidade com o fazer jornalístico concomitantemente com o literário.

Como lembrado anteriormente, Alcantara Machado (1935) menciona que as modinhas paulistanas tiveram influência em sua produção como escritor. Ao longo de suas observações sobre tal fazer, ele deixa bem claro a motivação sentimental por trás de sua pesquisa, no que toca o peso do contato com as modinhas paulistanas em sua 
formação. Das comparações do liricismo amador dos compositores com seu próprio ímpeto de tatear as letras, a proximidade fica evidente a cada momento que ele esmiúça as características que compõem as modinhas paulistanas. Se isso nem sempre fica evidente na leitura de seu estudo, é perceptível quando confrontamos alguns dos atributos elencados com sua própria obra literária. No que concerne aos aspectos gerais do que é comum entre ambos, o autor faz referência a como o ímpeto jornalístico dessas modinhas corresponde a uma tendência à narrativa.

O que distingue também o trovador paulistano (mas não ele só, pois também o canto nordestino se dá a mesma cousa embora sem o caráter marcado característico daquele) é a ausência de qualquer nota amorosa. Poesia sentimental, se quizerem piegas, porém desamorosa. Por que jornalística? Pode bem ser. Poesia de fatos diversos não canta as expressões íntimas. Não canto o amor. Quando vem ao caso conta o amor. Como um antecedente. (...) A modinha que se trata aqui é em suma uma exploração do sentimento popular provocado por um acontecimento. Aproveita-se a sensação causada por um feito de aviação. Aproveita-se ao mesmo tempo o sucesso de uma música. E lança-se a modinha (MACHADO, 1935, p. 192).

Essa narratividade sóbria, desencantada, é o que identifica o pendor da modinha paulistana para a sátira. Não apenas pelo aspecto paródico do reaproveitamento de melodias da canção de massas. Esse movimento de aproximar o veículo da informação da oralidade e da cotidianidade condiciona a um limiar entre a frieza jornalística e o apelo à experiência da narrativa que só vem a ser realizado através da tendência à sátira. São aspectos que Antônio de Alcantara Machado irá incorporar a sua obra escrita.

Do que decorre a proximidade com as modinhas, a obra mais famosa de Antônio Alcantara Machado, "Brás, Bexiga e Barra Funda", é a que demonstra incorporar mais claramente algumas de suas características. É uma obra conceitual, no sentido de que 
todos os contos se referem à cotidianidade da comunidade ítalo-paulistana. Com tais ações o autor procede num movimento de devir sobre a comunidade escolhida: imigrantes e seus descendentes que não obstante a ruptura causada pela imigração, ainda tinham de lidar com um período de transição entre rural e urbano no novo país. Incorporar os anseios dessa comunidade significa procurar capturar as nuances de um fluxo cultural ainda indefinido e que reflete a incerteza do imaginário subalterno no novo contexto urbano.

Essa noção de uma modernidade ordinária é o que leva a conexão de “Brás, Bexiga e Barra Funda" com os aspectos ditos jornalísticos identificados por Alcantara Machado nas modinhas paulistanas, no que prima que sua vinculação da experiência a uma descrição informativa da vida urbana é o que permite ao próprio escritor qualificar sua obra como "acontecimentos de crônica urbana" (1983, p.24). Mas se existe algo que as aproxima realmente é o sensacionalismo. "Brás, Bexiga e Barra Funda" é rica em casos cujo desfecho é a tragédia urbana, sempre exagerando seus aspectos. Caso do conto do "Gaetaninho". A história do menino maroto que sonha em andar de carro poderia ser apenas uma história singela dos pormenores do cotidiano. Mas se converte em um caso de humor negro quando o garoto, que apreciava os enterros, pois eram um dos poucos eventos onde um carro era utilizado, é atropelado por um bonde e surge depois na iminência de seu próprio enterro. Como em um jornal marrom, o autor é detalhista e apelativo ao comentar o enterro do rapaz.

Às dezesseis horas do dia seguinte saiu um enterro da Rua do Oriente e Gaetaninho não ia na boleia de nenhum dos carros do acompanhamento. la no da frente dentro de um caixão fechado com flores pobres por cima. Vestia a roupa marinheira, tinha as ligas, mas não levava a palhetinha (MACHADO, 1983, p. 29). 
A proximidade com as modinhas paulistanas é realçada conforme Alcantara Machado adentra no tema dos crimes domésticos. Como visto anteriormente, casos de assassinatos em que um marido mata sua mulher são frequentes nas temáticas das referidas modinhas. Isso leva José Vinci de Moraes a compreender que nessas modinhas está presente "a clássica relação entre amor, medo e tragédia, típicas do romantismo, com temas exageradamente mórbidos" (2000, p. 158). São aspectos que também se mostram presentes nas histórias de "Brás, Bexiga e Barra Funda", apesar também da presença de certa comicidade. A narrativa tragicômica poderia ter, portanto, muito mais a ver com a ligação de certa tradição literária urbana ao popular do que algo direto com as modinhas paulistanas. Porém, se tais características podem servir apenas como pistas de certa influência, um conto sugestivamente intitulado "Amor e Sangue" deixa clara a marca que aquelas modinhas imprimiram na obra de Alcantara Machado. A história de um rapaz cuja paranoia em relação ao fim da relação o leva a assassinar a ex-namorada termina com uma referência evidente.

-Eu a matei porque estava louco, seu delegado!

Todos os jornais registraram essa frase que foi dita chorando.

Eu estava louco,

Seu delegado!

Matei por isso,

Sou um desgraçado!

O estribilho do ASSASSINO POR AMOR (canção da atualidade para ser cantada com a música do FUBÁ, letras de Spartaco Novais Panini) causou furor na zona.

(MACHADO, 1983, p. 51-52).

É evidente a referência às modinhas paulistanas no encerramento desse conto. A forma como o autor as conecta esse fazer ao tema que lhe é caro, não apenas fortalece o 
aspecto de homenagem, como também as situa como um fazer cultural que responde a situação social que as envolve. Afinal, o que cativa Antônio de Alcantara Machado a estudar essa forma rudimentar de canção é sua capacidade de transformar em lírica os temas difíceis da convivência moderna e que estariam necessariamente vinculados ao meio da informação noticiosa.

\section{Conclusão}

A pesquisa realizada por Antônio de Alcantara Machado é um documento essencial para entender a formação cultural de uma cidade na transição do agrário para o moderno. As ditas modinhas paulistanas coletadas pelo autor são alguns dos exemplares mais evidentes de manipulação que populares podem fazer de signos que thes são induzidos em uma modernidade ainda por definir. O esforço de artistas urbanos que circulavam em São Paulo na primeira metade do século XX em sintetizar elementos difusos e diferentes entre si na esperança de compreender melhor a nova situação urbana foi fundamental na formação de uma lírica própria do paulistano.

Não obstante o detalhe de como essas modinhas são reveladoras de como o paulistano enxergava e interagia com a própria cidade, sua conexão com o próprio Antonio Alcantara Machado também esclarece sobre tal situação. De como sua principal motivação para a pesquisa foi sentimental, trata-se de um detalhe relevante para compreender um dos pioneiros da crônica paulistana. Quando analisamos "Brás, Bexiga e Barra Funda", é perceptível como Alcantara Machado dialogou com as modinhas paulistanas no que diz respeito a traçar um retrato da nova São Paulo. No que tange à sensibilidade de uma realidade confusa, onde a modernização ainda havia de superar a 
ordem agrária, esse choque entre paradigmas se traduziu em uma narrativa informativa que veio a definir o discurso ordinário sobre a cidade.

\section{Referências}

ARRIGUCCI JR, Davi. Achados e perdidos: ensaios de crítica. São Paulo: Editora Polis Ltda, 1979.

BENJAMIN, Walter. Obras escolhidas - Volume - I. Magia e técnica, arte e política: ensaios sobre literatura e história da cultura. Tradução de Sérgio Paulo Rouanet. 7 ed. São Paulo: Brasiliense, 2012.

- Obras escolhidas - Volume III. Chalés Baudelaire: um lírico no auge do Capitalismo. Tradução de José Martins Barbosa, Hemerson Alves Batista. São Paulo: Brasiliense, 1994.

BULHÕES, Marcelo. Jornalismo e literatura em convergência. São Paulo: Ática, 2007.

LÉVI-STRAUSS, Claude. O pensamento selvagem. Tradução de Tânia Pellegrini. 12 ed. Campinas, SP: Papirus, 2012.

NAVES, Santuza Cambraia. A canção brasileira: leituras do Brasil através da música.

Organização de Frederico Coelho. Rio de Janeiro: Zahar, 2015.

MACHADO, Antônio Alcantara. Lira Paulistana. Revista do arquivo municipal. v. XVII. São Paulo: Departamento de Cultura, 1935.

Brás, Bexiga e Barra Funda. Apresentação e notas de Francisco Achcar. São Paulo: Objetivo, 1983.

MOÍSES, Massaud. A criação literária. 11 ed. São Paulo: Cultrix, 1982.

MORAES, José Geraldo Vinci de. Metrópole em sinfonia: história, cultura e música popular na São Paulo dos anos 30. São Paulo: Estação Liberdade, 2000. 
'O presente trabalho foi realizado com apoio do CNPq, Conselho Nacional de Desenvolvimento Científico e Tecnológico - Brasil.

Recebido em 30 de outubro de 2017.

Aceito em 30 de dezembro de 2017. 